\title{
A GEODATABASE FOR MULTISOURCE DATA APPLIED TO CULTURAL HERITAGE: THE CASE STUDY OF VILLA REVEDIN BOLASCO
}

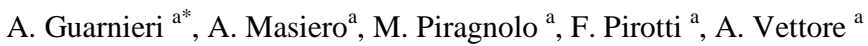 \\ ${ }^{a}$ CIRGEO, Interdepartment Research Center of Geomatics, University of Padua, Viale dell'Università 16, Legnaro (PD) 35020, Italy \\ (alberto.guarnieri, cirgeo) @unipd.it
}

Commission V, WG V/2

KEY WORDS: Cultural Heritage, 3D Modeling, laser scanner, geodatabase, Web World Wind

\begin{abstract}
In this paper we present the results of the development of a Web-based archiving and documenting system aimed to the management of multisource and multitemporal data related to cultural heritage. As case study we selected the building complex of Villa Revedin Bolasco in Castefranco Veneto (Treviso, Italy) and its park. Buildings and park were built in XIX century after several restorations of the original XIV century area. The data management system relies on a geodatabase framework, in which different kinds of datasets were stored. More specifically, the geodatabase elements consist of historical information, documents, descriptions of artistic characteristics of the building and the park, in the form of text and images. In addition, we used also floorplans, sections and views of the outer facades of the building extracted by a TLS-based 3D model of the whole Villa. In order to manage and explore these rich dataset, we developed a geodatabase using PostgreSQL and PostGIS as spatial plugin. The Web-GIS platform, based on HTML5 and PHP programming languages, implements the NASA Web World Wind virtual globe, a 3D virtual globe we used to enable the navigation and interactive exploration of the park. Furthermore, through a specific timeline function, the user can explore the historical evolution of the building complex.
\end{abstract}

\section{INTRODUCTION}

In the last decade improvements in surveying techniques (e.g. Terrestrial Laser Scanning-TLS, close range photogrammetry) and in digital data processing and management have allowed to collect different kind of information about a Cultural Heritge object. Whether it is a simple statue, a small artifact, a fragment or a whole ancient building or archeological site, current digital technology provides the users (scholars, professionals or wider audience) many instruments to analyze, study and explore the historical good. For example, through the generation of multiresolution digital 3D models, geometrical, spatial, radiometric and multispectral contents of investigated objects can be captured and stored in digital form for documentation and conservation purposes. Three-dimensional modelling and representation through laser scanner surveys is a widely used method in the field of architecture and cultural heritage. It is well known that TLS technique not only provides information about the geometry of the object of interest, but also it enables to extrapolate information abut the state of conservation directly in a $3 \mathrm{D}$ environment. Moreover, in last years the integration between laser scanning technology and photogrammetry has also proven to be a very effective methodology to provide highresolution 3D models of heritage sites and cultural artifacts. Through this approach, the geometry and appearance of real objects can be recorded with high level of detail and accuracy. Several works published so far have demonstrated how Cultural Heritage $(\mathrm{CH})$ can greatly benefit from 3D modeling applied to object or historical/ archaeological site analysis, documentation, preservation and restoration (Barber et al. 2001, Guarnieri et al. 2004, Beraldin et al. 2005, Remondino et al. 2008). For instance, working in a $3 \mathrm{D}$ environment allows to digitally remove unwanted elements from the model and to view the object/site in his correct historical context. Virtual restoration can be used to improve the knowledge of a site without resorting to interventions often traumatic for the original artifact. Furthermore, $\mathrm{CH}$ can also benefit from the use of
Virtual Reality (VR) and its integration with Hypermedia and Computer Graphics (CG). The advantages of using these technologies include the virtual reconstruction of buildings, sites or objects that no longer or only partially exist, the simulation of viewpoints not available in the real world, the direct interaction with virtual reproductions of artifacts, thus eliminating the risk of degradation. Virtual Reality environments created around such 3D models represent very often an easy way to give accessibility to $\mathrm{CH}$ among a wide variety of users.

Other than surveying techniques, further data sources for the documentation of $\mathrm{CH}$ goods are represented by historical images and construction plans (in case of buildings or historical sites). By integrating in a proper database all these datasets, a complete knowledge of the object of interest from the geometric, spatial, and temporal viewpoint can be provided to the users. For example, as denoted in (Gianninetto et al. 2006), a database containing georeferenced 3D point clouds could be used as Spatial Information System in the field of Architecture for classifying structural elements or determining the state of decay or conservation of each part of the object of study. Besides the developments occurred in the field of survey, the growing availability of faster Internet connections and of more performing servers and browsers represents another key factor for the dissemination of 3D models to a wider audience through the Internet. Web-based applications have indeed many advantages as compared to standalone solutions, such as no need for installing large external programs, use of a common web browser with light plug-ins, cross-platform and centralized administration for data update, backup and storage.

In this paper we present the results of the development of a Web-based archiving and documenting system aimed to the management of multisource and multitemporal data related to cultural heritage. As case study we selected the building complex of Villa Revedin Bolasco in Castelfranco Veneto (Treviso, Italy) and its park. By interactively querying the database, the user can access different types of information 
about the Villa and therefore extract different levels of knowledge regarding this ancient, historical building.

\section{THE STUDY SITE: VILLA REVEDIN BOLASCO}

Villa Revedin-Bolasco and its Park, used to be known as "the Paradise", are located in Castelfranco Veneto, a small historic walled town in the Veneto region of northern Italy, in the province of Treviso (Figure 1). The Villa was built between 1852 and 1865 on design of architect Giambattista Meduna famous for the drawings of the La Fenice Theater in Venice - by order of Count Francesco Revedin (1811-1869), the podestà and first mayor of Castelfranco in 1866. The Villa contains one hundred and thirty rooms distributed on three floors, among which the dance-hall painted by Giacomo Casa, and the stylish stables are well worth a look (Figures 2 - 4). Count Revedin also ordered a Romantic English garden to replace the Corner "Paradise", known as the Revedin-Bolasco Park designed by Meduna and other famous landscape designers of the day, including Francesco Bagnara and Marc Guignon from France. An aerial view of the building complex (Villa and Park) is shown in figure 5 .

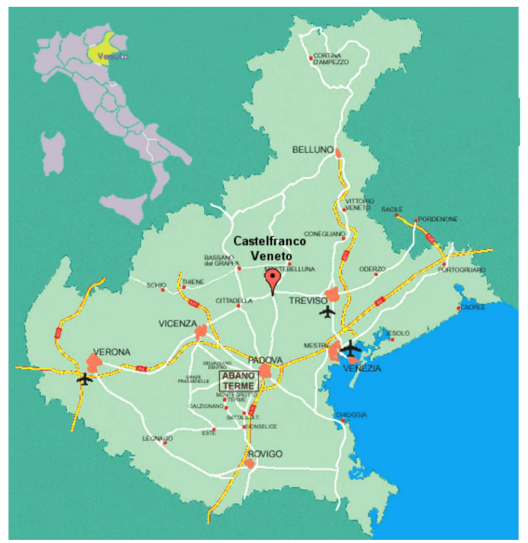

Figure 1: Geographic location of Castelfranco Veneto, Italy.

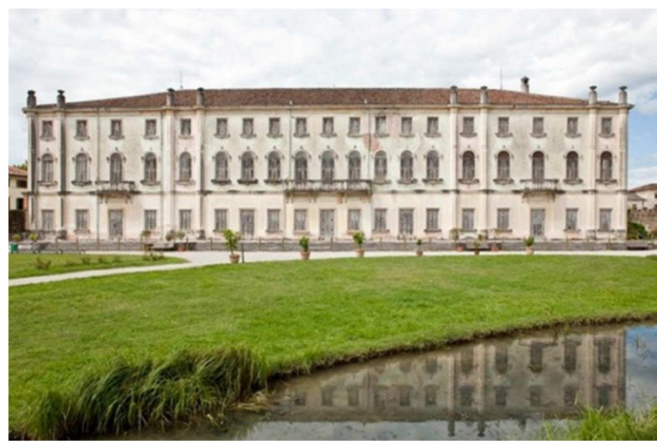

Figure 2: View of the "summer" wing of Villa Bolasco.

A stroll round the Park reveals enchanting views dappled with rays of light, ever-changing shades and colours, trees and ponds, meadows and thickets, small bridgesand man-made hillocks. Buildingsare dotted here and there: the Hispanic-Moresque style greenhouse, a "cavana" (hut), the tower, and lastly, to the north, a true masterpiece, the so-called "arena-cavallerizza" (Figure 6), Count Revedin's beloved riding ground featuring dozens of statues from the 17th century by Orazio Marinali from Bassano and his apprentices, and two equestrian statues on high plinths. Statues, horses, and the Western gate dovecot tower are all that remain of the Corner "Paradise garden", where the 15th-16th century family villa and annexes were located in the area of the park. The Park, extending over an area of 7.63 hectares, boasts over 1,000 trees of 65 different species, 35 of which are between 75 and 125 years old, as well as 440 plants ranging from 50 to 70 years old.

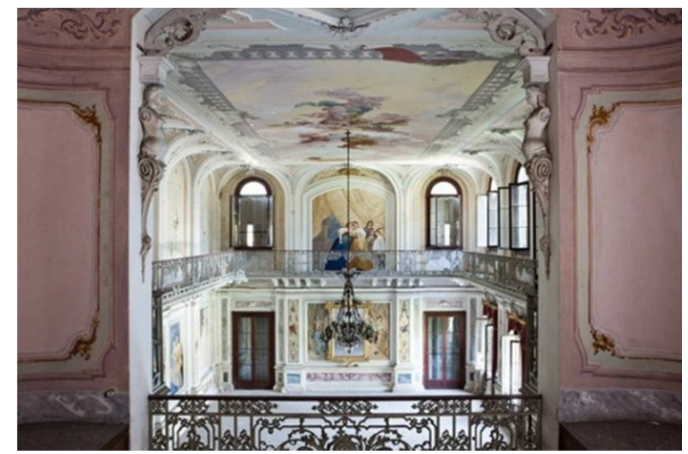

Figure 3: Upper view of the dance hall of Villa Bolasco.

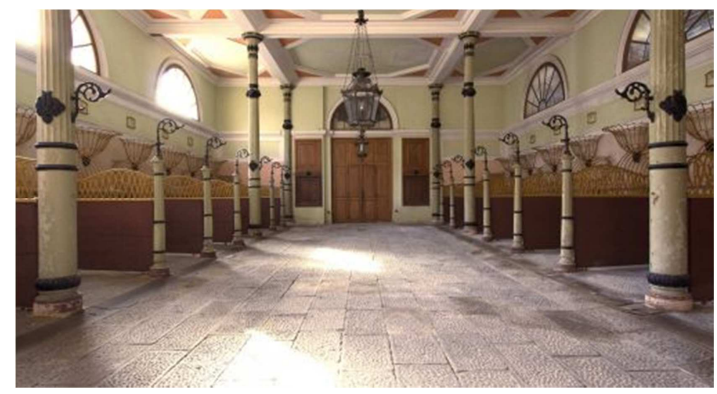

Figure 4: The stables.

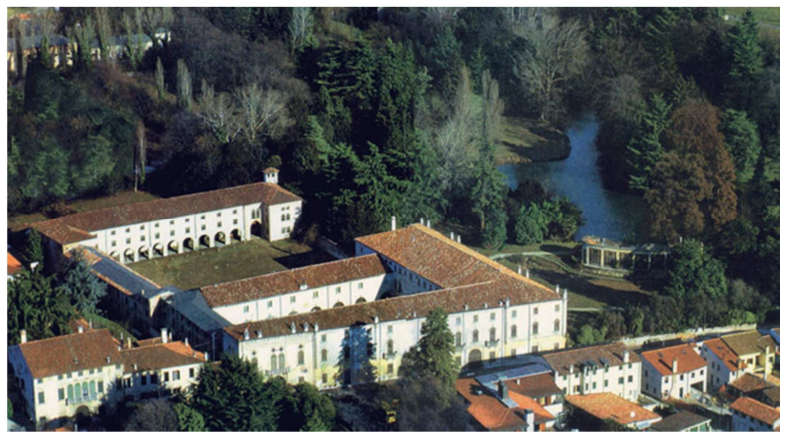

Figure 5: Aerial view of the complex building of Villa Bolasco and the Park.

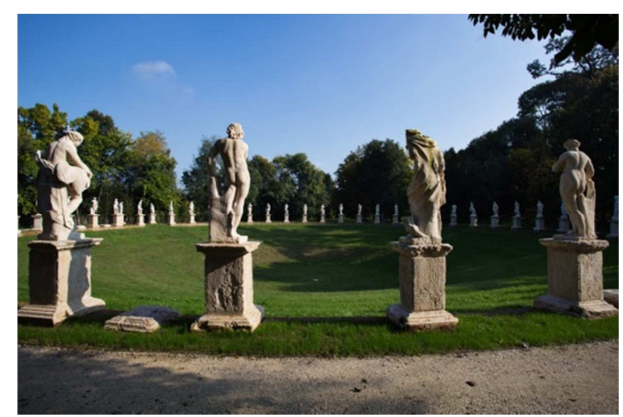

Figure 6: View of the arena-cavallerizza. 


\section{MATERIAL AND METHODS}

The data management system relies on a geodatabase framework, in which different kinds of datasets were stored. More specifically, the geodatabase elements consist of historical information, documents, descriptions of artistic characteristics of the building and the park, in the form of text and images. In addition, we used also floorplans, sections and views of the outer facades of the building extracted by a TLS-based 3D model of the whole Villa. Top-view images of the building complex were collected by an Unmanned Aerial Vehicle (UAV). The employed datasets are listed in Table 1.

\begin{tabular}{|c|c|c|c|}
\hline Dataset & Type & Structure & File format \\
\hline $\begin{array}{c}\text { Historical } \\
\text { informations }\end{array}$ & documents & text & - \\
\cline { 2 - 4 } & images & raster images & .jpg, .png, .tif \\
\hline Floorplans & images & $\begin{array}{c}\text { vector } \\
\text { images }\end{array}$ & .dwg \\
\hline Sections & images & $\begin{array}{c}\text { vector } \\
\text { images }\end{array}$ &. dwg \\
\hline Views & images & $\begin{array}{c}\text { vector } \\
\text { images }\end{array}$ &. dwg \\
\hline Pictures & images & raster images & .jpg, .tif, .geotif \\
\hline Videos & video & video format & .avi, .mp4 \\
\hline Thesis & documents & text & .pdf \\
\hline $\begin{array}{c}\text { Points of } \\
\text { interest }\end{array}$ & location & coordinates & - \\
\hline \multirow{2}{*}{ Park maps } & images & $\begin{array}{c}\text { vector } \\
\text { images }\end{array}$ & .shp \\
\hline \multirow{2}{*}{ Restorations } & documents & text & .doc, docx., pdf \\
\cline { 2 - 4 } & images & $\begin{array}{c}\text { vector } \\
\text { images }\end{array}$ &. dwg \\
\cline { 2 - 4 } & images & raster images & .jpg, .png, .tif \\
\hline
\end{tabular}

Table 1. List of datasets of Villa Revedin Bolasco

Datasets contain also spatial information, and for this reason we adopted a geodatabase. To manage and explore these rich dataset we used PostgreSQL 9.4.6 and PostGIS 2.2.1 plugin. The structure of geodatabase is described in Figure 7.

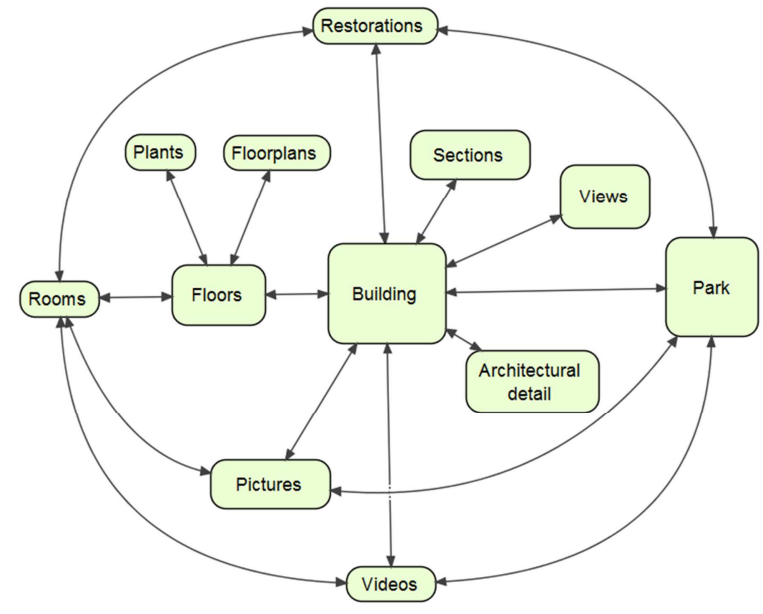

Figure 7. Conceptual model of the database. language, and phpPgAdmin to 5.1 (Bitnami, 2016). It is accessible from server side (through phpPgAdmin) or client side. PhpPgAdmin is a library that provides a graphic interface for a user-friendly management of database such as modification of tables or visualization of information. Information could be extracted by setting a specific query in SQL language. From client side the data can be accessed by the user through a Web-GIS platform. The Web-GIS was developed in HTML 5 and JavaScript languages, and it contains five tabs: floorplans, sections, park, timeline, data download, phpPgAdmin. These tabs are described in the following.

The Floorplans tab is an interactive Scalable Vector Graphics (SVG) layer of floorplan. Floorplans were extracted from a TLS-based 3D model of the whole Villa, performed with a Leica C10 laser scaner. User can select, with the mouse, an element of the layer, e.g. the polygon representing a room of the Villa, and all related available information are displayed in the form of images and tabular data.

Park tab shows information related to italian-style garden that has a size more than eight hectares. User can select a point of interest on Web World Wind map. Web World Wind is a virtual globe used for the navigation and interactive exploration of the park. It was developed by NASA in JavaScript language in order to create interactive visualizations of geographic information on an interactive 3D globe or 2D map (Bell et al., 2007, Hogan, 2009, Nasa, 2016). It displays a large collection of high-resolution imagery and terrain, geometric and geographic shapes for representing information such as polygons, paths, placemarks, and shapefile. The virtual globe works in WGS84 reference system and support Web Map Service. It is simple to install and modify, and provides a good alternative to widespread OpenLayers map library.

Information of park and buildings can be visualized in space and in time. To this aim the TimelineJS plugin was integrated in the Web-GIS. This plugin is an open-source tool based on JavaScript Object Notation (knew as JSON) useful to visualize interactive timelines (Northwestern University Knight Lab, 2015) where the information is extracted from geodatabase combining JSON with PHP.

Data download tab provides a list of available resources. The list is automatically generated through a specific script, which query the database.

PhpPgAdmin tab allows, to an authorized user, to access to the database from client mask.

\section{RESULTS}

In this section we illustrate the main windows of the Web-GIS. Figure 8 shows the homepage of Villa Revedin Bolasco WebGIS. The blue area indicates the five tabs of the system: floorplans, sections, park, timeline, data download, phpPgAdmin.

Floorplans sections and views are drawn in SVG format and can be explored with the appropriate visual commands or by mouse. SVG drawings are obtained by transformation of original Computer-aided design (CAD) floorplans. Each room is identified by a code. Clicking on the code, information is displayed to the user in the form of images and tabular data as shown in Figures 9 and 10.

The geodatabase was implemented on WAPP Stack 5.6.18-1, that integrates Apache server 2.4.18 PHP 7.0.3 programming 


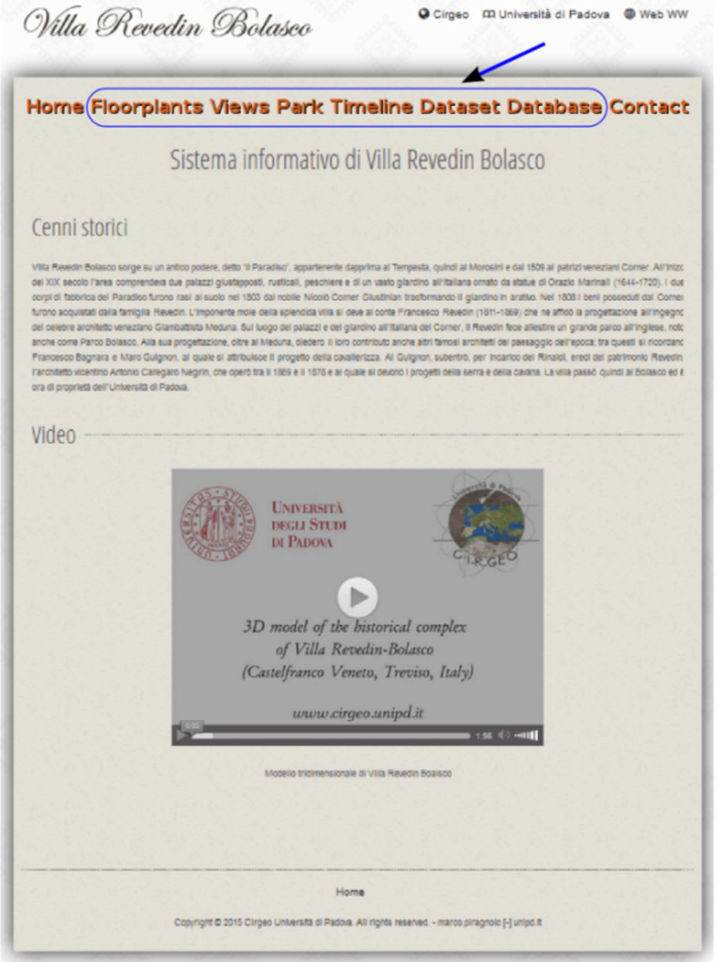

Figure 8. Home page of Web-GIS of Villa Revedin Bolasco. The blue area highlights the main tabs.

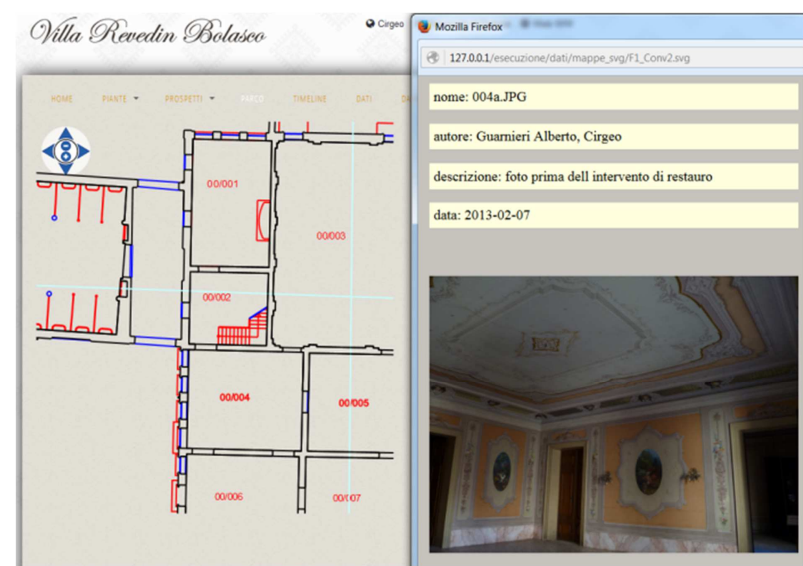

Figure 9. Floorplans navigation and query.

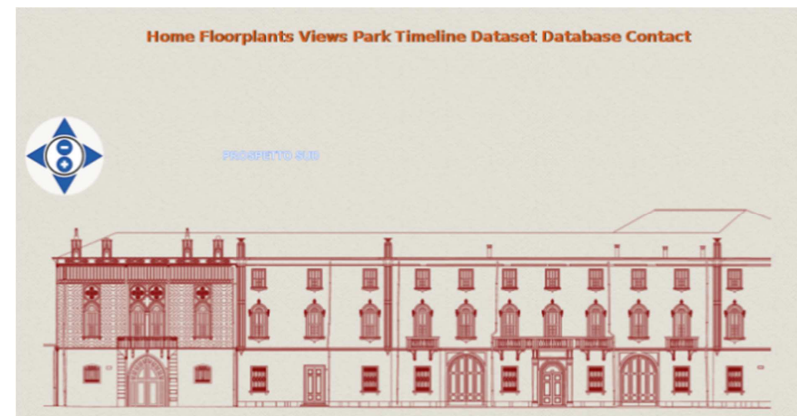

Figure 10. SVG view of Villa Revedin Bolasco.

Figures 11 and Figure show an example of the points of interest available on Web World Wind map for the park of Villa Ravadin Bolasco. Default layers are Blue Marble, Blue Marble and Landsat, Bing Aerial, Open Street Map and Digital Elevation Model. We added three layers such as park and buildings perimeters and point of interest extracted from geodatabase. Placemark position is obtained from geodatabase through a spatial query that merges historial information, spatial information and picture. Clicking on the code information is displayed to the user in the form of images and tabular data.

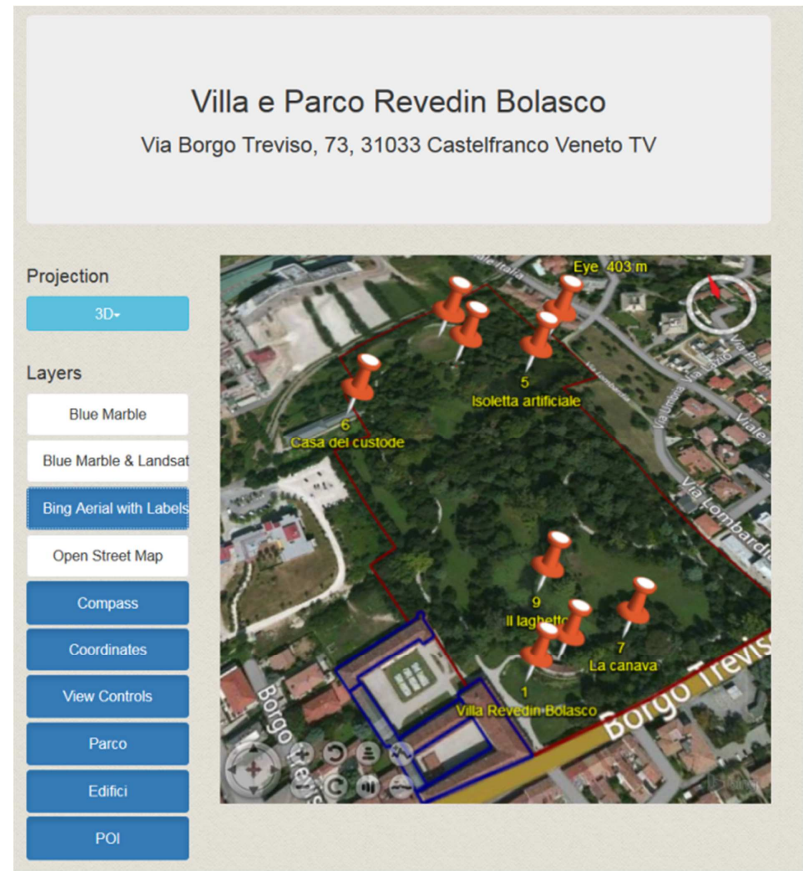

Figure 11. Point of interest displayed as Web World Wind placemark.

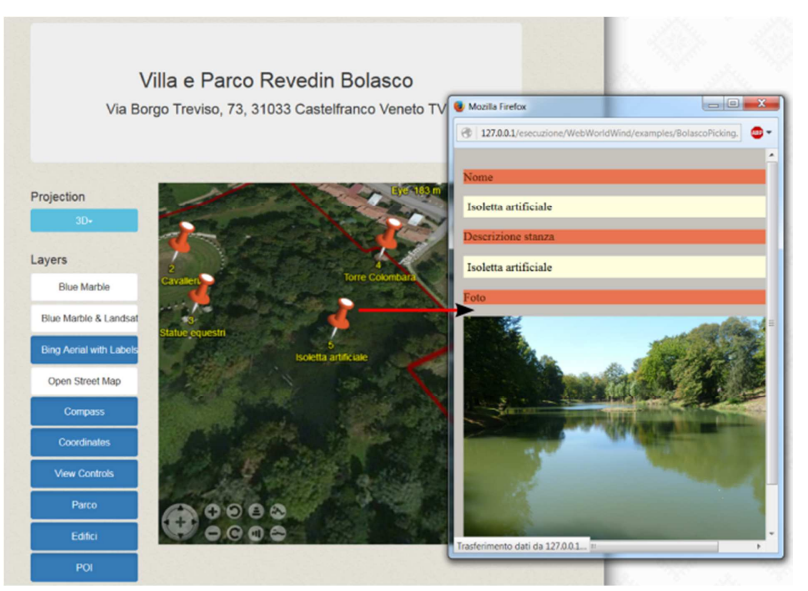

Figure 12. Information linked to a placemark.

A timeline provides information of the area through the temporal scale. The origin of area, called "Paradiso dei Tempesta" can be traced back to XV century, and in six hundreds centuries many restorations and transfer of ownership have been occurred. The Timeline plugin enables to navigate forward or backward in time, display information or images related to each event and stored in database (Figure 13).

Datasets are also available for download in specific section. The list is automatically generated and updatedas shown in Figure 14. 


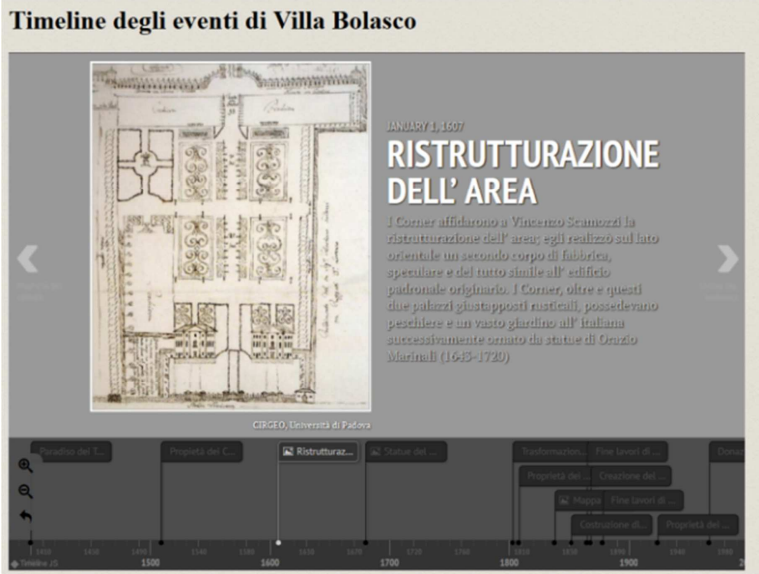

Figure 13. The timeline bar displaying as et of events related to Villa Revedin Bolasco.

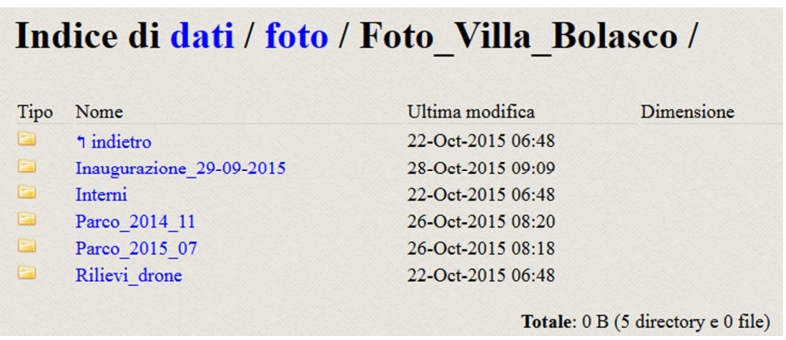

Figure 14. Example of resources available for download.

The geodatabase can be managed and explored as client service through phpPgAdmin. A registered and authorized user can login and execute query, create new table, fill new information or delete wrong one by a graphic user-friendly interface or by SQL console (Figure 15).

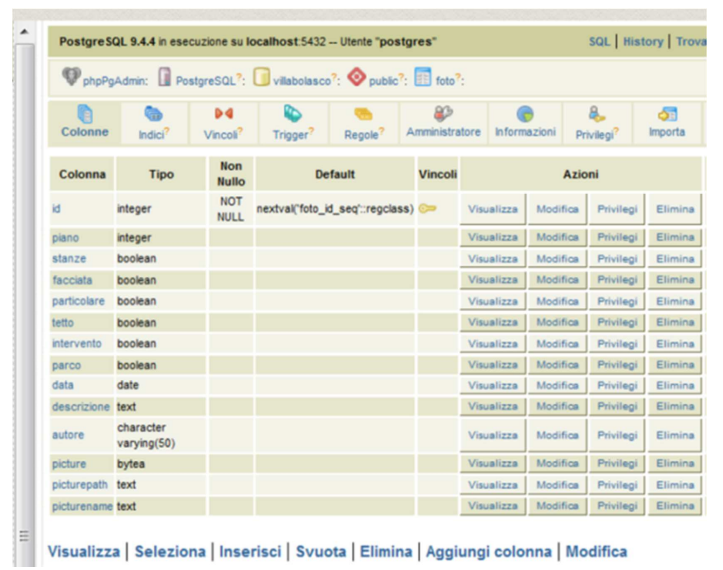

Figure 15: The PhpPgAdmin window.

\section{CONCLUSIONS}

In this paper we have presented the results of the development of a Web-based archiving and documenting system for managing multisource and multitemporal data related to cultural heritage. The data management system relies on a geodatabase framework, in which different kinds of datasets were stored. More specifically, the geodatabase elements consist of historical information, documents, floorplans extracted from a TLS-based
3D model, descriptions in the form of text and images of artistic characteristics of building complex of Villa Revedin Bolasco, an ancient historical venetian villa located in Castefranco Veneto (Treviso, Italy). In order to manage and explore these rich dataset, we developed a geodatabase using PostgreSQL and PostGIS as spatial plugin. The Web-GIS platform, based on HTML5 and PHP programming languages, implements the NASA Web World Wind virtual globe, a 3D virtual globe we used to enable the navigation and interactive exploration of the park, which is part of the complex. Through specific queries of the database or by using a timeline function, the user can explore the Villa under different perspectives (geometric, spatial, temporal) and extract different levels of knowledge.

\section{REFERENCES}

Barber, D., Mills, J., Bryan P. G., 2001. Laser Scanning and Photogrammetry-21th Century Metrology. Proc. of CIPA 2001 Int. Symposium "Surveying and Documentation of Historic Buildings, Monument", Potsdam, Germany.

Bell, D.; Kuehnel, F.; Maxwell, C.; Kim, R.; Kasraie, K.; Gaskins, T.; Hogan, P.; Coughlan, J., 2007. NASA WW: Opensource GIS for mission operations. In: Proceedings of the 2007 IEEE Aerospace Conference, Big Sky, MT, USA, Volumes 1-9, pp. 4317-4325

Beraldin, J.-A., Picard, M., El-Hakim, S., Godin, G., Borgeat, L., Blais, F., Paquet, E., Rioux, M., Valzano, V., Bandiera, A., 2005. Virtual Reconstruction of Heritage Sites: Opportunities and Challenges Created by 3D Technologies. Proc. of the International Workshop on "Recording, Modeling and Visualization of Cultural Heritage", Ascona, Switzerland.

Bitnami, WAPP Stack Cloud Hosting, WAPP Stack Hosting Installers and VM, 2016. Available from: https://bitnami.com/stack/wapp. Accessed on February 2016.

Gianninetto M., Giussani A., Roncoroni F., Scaioni M, 2006. Integrazione di differenti tecniche di acquisizione dati per l'analisi diagnostica 3D di un oggetto architettonico. Proc. of VIII ASITA Conference, Rome, Italy

Guarnieri, A., Remondino, F., Vettore, A., 2004. Photogrammetry and Ground-based Laser Scanning: Assessment of Metric Accuracy of the 3D Model of Pozzoveggiani Church. Proc. of FIG Working week 2004, "The Olympic Spirit in Surveying”, Athens, Greece.

Hogan, P., Gaskins, T., 2009. GeoSpatial Visual Analytic: Geographical Information Processing and Visual Analytics for Environmental Security. R. De Amicis, R. Stojanovic, \& G. Conti eds., Springer Science \& Business Media.

Nasa, Web World Wind. Nasa World Wind for Javascript, 2015. Available from: https://webworldwind.org/. Accessed on February 2016.

Northwestern University Knight Lab, Web Timeline JS - Knight Lab, 2015. Available from: https://timeline.knightlab.com/. Accessed on February 2016.

Remondino, F., Girardi, S., Gonzo, L., Rizzi, A., 2008. Multiresolution modeling of complex and detailed Cultural Heritage. Proc. of $9^{\text {th }}$ Int. Symposium on Virtual Reality, Archaeology and Cultural Heritage (VAST 2008), pp. 1-8, Braga, Portugal. 